\title{
DITRANS - A Multi-agent System for Integrated Diagnosis of Power Transformers
}

\author{
Diego R. Morais, Jacqueline G. Rolim, and Zita A. Vale
}

\begin{abstract}
This paper describes the development and the implementation of a multi-agent system for integrated diagnosis of power transformers. The system is divided in layers which contain a number of agents performing different functions. The social ability and cooperation between the agents lead to the final diagnosis and to other relevant conclusions through integrating various monitoring technologies, diagnostic methods and data sources, such as the dissolved gas analysis.
\end{abstract}

Index Terms - Power Transformers, Multi-agent System, Online and Off-line diagnosis and monitoring methods.

\section{INTRODUCTION}

U sually power transformers have a 20-35 year design life. In practice, a transformer can reach 60 years of useful life if it is properly operated and maintained. With the normal aging, their internal condition degrades, which increases the risk of failure. Traditionally, the evolution of these faults was accompanied with preventative maintenance programs combined with regular tests. With deregulation, it has become necessary to reduce maintenance costs and equipment inventories, thus there is a trend in the industry to move from traditional time-based maintenance programs to conditionbased maintenance [1].

The use of on-line and off-line monitoring methods of power transformers is increasing steadily. The combination of on-line monitoring and off-line diagnosis can provide a powerful tool for the complete and economic assessment of power transformers, strongly reducing the risk of severe failures [2]. However, the management of supervised data is rather difficult because they are spread over several laboratories and departments. There is a lack on how to manage the information provided by the monitoring systems in order to take decisions that lead to effective actions for the equipment.

This paper presents a multi-agent system for integrated diagnosis of power transformers named DITRANS, considering information from on-line monitoring devices and off-line diagnostic methods, such as: frequency response

D. R. Morais is with the Polytechnic Institute of Porto, Porto, Portugal and with Federal University of Santa Catarina, Florianópolis, Brasil (e-mail: drmo@isep.ipp.pt). The first author acknowledges the Brazilian Research Council (CNPq) for his financial support.

J. G. Rolim is with Federal University of Santa Catarina, Florianópolis, Brasil (e-mail: jackie@1abspot.ufsc.br).

Z. A. Vale is with the Polytechnic Institute of Porto, Porto, Portugal (e-mail: zitavale@sapo.pt). analysis (FRA), recovery voltage measurement (RVM), dissolved gas analysis (DGA), power factor vs. frequency measurement, among others. DITRANS assists operators providing them with the results of an intelligent analysis of the available data. These results both from agents devoted to specific diagnostic methods and to cooperation and competition processes among agents, each one using the relevant information with which it can draw conclusions.

In order to evaluate the performance of this system, a database, with results of real oil analysis and simulated samples of frequency response analysis, has been employed. The main objective of the proposed tool is to provide more conclusive and reliable diagnosis about the transformer state, supporting decisions concerning its maintenance schedule.

\section{II.ASSESSMENTS OF POWER TRANSFORMERS IN SERVICE}

In practice, assessments of the transformers conditions may be performed for any of the following reasons [3]: to monitor the transformer condition and possibly detect incipient faults; to diagnose problems when a transformer exhibits danger signals or following the operation of their protection devices; to determine whether a transformer is in condition to cope with unusual operating conditions; to satisfy the requirements for insurance cover; to obtain reference results to assist in the interpretation of subsequent tests; and to assist in planning the replacement strategy for a population of transformers.

In this context, the evaluation of power transformers conditions is related to the condition of their main components, which ensure the normal operation of transformers. Failure statistics of large transformers can be beneficial in determining which component is more important to evaluate the condition of the equipment [4]. Figure 1 [5]

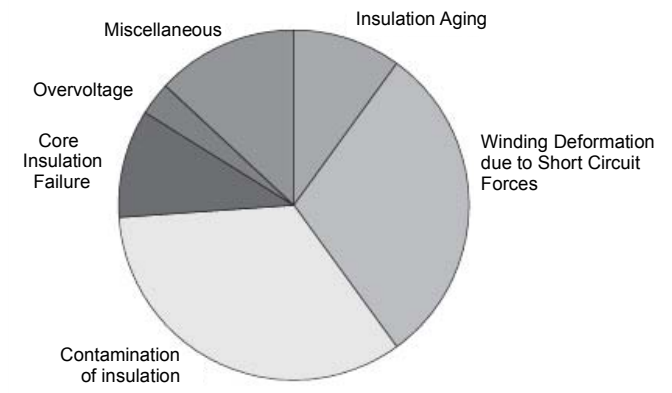

Fig. 1. Failure of transformers 15 to 25 years old. [5] 
TABLE I

TRANSFORMER COMPONENTS, THEIR DEFECTS AND MONITORING AND DIAGNOSTIC METHODS

\begin{tabular}{|c|c|c|}
\hline COMPONENTS & DEFECTS & MONITORING AND DIAGNOSTIC METHODS \\
\hline \multirow[t]{2}{*}{ OLTC } & Contact faults & $\begin{array}{l}\text { Measure the temperature difference between OLTC compartment and the } \\
\text { main tank. }\end{array}$ \\
\hline & Mechanical faults & Monitoring of the motor current. \\
\hline \multirow[t]{2}{*}{ BUSHING } & Moisture & Power Factor (PF); Capacitance (C); Dissipation Factor (tg $\delta)$. \\
\hline & Partial Discharges & $\mathrm{PF} ; \mathrm{C} ; \operatorname{tg} \delta$ \\
\hline \multirow[t]{5}{*}{ WINDINGS } & Overheating & Thermograph; Winding Resistance. \\
\hline & Anormal Electrical Lose & Load Losses. \\
\hline & $\begin{array}{l}\text { Axial and Radial Displacement (Mechanical } \\
\text { Deformation) }\end{array}$ & Frequency Response Analysis (FRA); Leakage inductance. \\
\hline & Dielectrical Degradation & Insulation Resistance (IR); Insulation Power Factor (IPF). \\
\hline & Winding Mechanical Faults & Electrical Resistance. \\
\hline $\begin{array}{l}\text { TANK AND } \\
\text { CONECTIONS }\end{array}$ & Anormal Currents at Tank & Infra-red emission. \\
\hline \multirow[t]{4}{*}{ SOLID INSULATION } & Moisture & $\begin{array}{l}\text { Recovery Voltage Method (RVM); Depolarization and Polarization Current } \\
\text { (PDC); Dissipation Factor (tg } \delta(\mathrm{f}) \text { ); FPIsol.; Furfural Analysis (2-fal). }\end{array}$ \\
\hline & Aging & Degree of Polymerization (GP); RVM; PDC; tg $\delta(f) ; 2$-fal. \\
\hline & Partial Discharge & Partial Discharges (PD); Dissolved Gas Analysis (DGA). \\
\hline & Overheating & DGA; Thermograph; 2-fal, FRA. \\
\hline \multirow[t]{5}{*}{ INSULATING OIL } & Moisture & Chemical and Physical Properties of Insulating Oil (C-P). \\
\hline & Overheating & DGA; Thermograph. \\
\hline & Arcing & DGA; C-P, FRA. \\
\hline & Aging & C-P; DGA. \\
\hline & Partial Discharge & DGA; DP; C-P. \\
\hline \multirow{4}{*}{$\begin{array}{l}\text { INSULATION AS A } \\
\text { WHOLE }\end{array}$} & Dielectrical Losses & $\operatorname{tg} \delta$; FPIsol. \\
\hline & Contamination & RIsol.; DP. \\
\hline & Moisture & RIsol.; $\operatorname{tg} \delta(f)$. \\
\hline & Deterioration & PD. \\
\hline CORE & Core faults & Magnetizing Current. \\
\hline
\end{tabular}

shows the results of a failure analysis carried out in South Africa, from 188 power transformers in the voltage and power range of $88 \mathrm{kV}$ to $765 \mathrm{kV}$ and $20 \mathrm{MVA}$ to $800 \mathrm{MVA}$, respectively.

For the development of transformers diagnostic tools, it has been essential to undertake a survey about the transformer main components, the associated defects and their diagnostic methods. This survey was based on publications on this subject [1-6], interviews with experts in power transformers and on a database of maintenance of power transformers obtained from a large transmission utility. The results of this survey are summarized in Table I.

In this table, only the main defects and their respective analysis methods are presented. These defects are divided into several types according to their nature (electrical, mechanical, thermal), the majority being related with the transformer insulation system.

Usually incipient faults of power transformers are classified into the following major categories [7, 8]: electrical arcing, electrical corona, overheating of cellulose and overheating of oil. These faults may occur due to one or more of the causes shown in Table II and can be related with other transformer components or its operation condition.

\section{A. Diagnostic and Monitoring Systems}

The monitoring and evaluation of a transformer state through on-line sensors assembled in transformers has been gradually incremented. The operation of these sensors is based on the monitoring of different quantities, such as current, voltage, the amount of gases dissolved in the oil, etc. Although these sensors do not have the function of protecting power transformers, they can detect the development of incipient faults before they evolve to a failure [1].

The most important test performed off-line that does not require the equipment outage is the dissolved gas analysis (DGA). There are many procedures and systems encountered in the literature for DGA data interpretation. These tools are based on methods described in standards or on artificial intelligence techniques. Morais and Rolim [9] presented a tool for diagnosing incipient faults in transformers through the analysis of dissolved gases in oil. This tool applies two standardized criteria (Rogers and Doernenburg) [8], a Brazilian standard (NBR 7274) [10], a General Regression Neural Network (GRNN) and a main fuzzy system, responsible for combining the outputs of the previous methods. This approach was designed to be used in a 
TABLE II

CORRELATION BETWEEN POWER TRANSFORMER INCIPIENT FAULTS AND CAUSES [7, 8]

\begin{tabular}{|c|c|c|c|c|}
\hline \multirow{2}{*}{ CAUSES } & \multicolumn{4}{|c|}{ FAULTS } \\
\hline & Arcing & Corona & Overheating of cellulose & Overheating of oil \\
\hline Winding turn-to-turn short-circuit & $\mathrm{X}$ & & $\mathrm{X}$ & \\
\hline Winding open circuit & $\mathrm{X}$ & & $\mathrm{X}$ & \\
\hline Operation of build-in LTC & $\mathrm{X}$ & & & \\
\hline Winding distortion or displacement & & $\mathrm{X}$ & $\mathrm{X}$ & \\
\hline Lead distortion or displacement & & $\mathrm{X}$ & $\mathrm{X}$ & \\
\hline Loose connection to bushing terminals, tap leads, terminal boards & $\mathrm{X}$ & $\mathrm{X}$ & $\mathrm{X}$ & \\
\hline Free water or excessive moisture in oil & $\mathrm{X}$ & $\mathrm{X}$ & & \\
\hline Floating metal particles & $\mathrm{X}$ & $\mathrm{X}$ & & \\
\hline Loose connection to corona shields & & $\mathrm{X}$ & & \\
\hline Loose collars, spacers, core ground straps, core hold down angle (Braces) & & $\mathrm{X}$ & & \\
\hline Through fault & & & $\mathrm{X}$ & \\
\hline Overloading & & & $\mathrm{X}$ & $\mathrm{X}$ \\
\hline Damaged yoke bolt insulation & & & & $\mathrm{X}$ \\
\hline Rust or other damage on core & & & & $\mathrm{X}$ \\
\hline Damaged shunt packs of tank & & & & $\mathrm{X}$ \\
\hline Jammed oil circulating path & & & & $\mathrm{X}$ \\
\hline Cooling system malfunction & & & & $\mathrm{X}$ \\
\hline
\end{tabular}

Transformer Monitoring Central. In this paper, a multi-agent approach is proposed to solve this problem and the methodologies cited above are applied separately, each one by an agent.

Other tests realized without necessity of equipment disconnection are the analysis of chemical and physical properties and furfural contents of the oil. These tests are also used by the multi-agent system.

In addition, there are tests executed with the equipment disconnected, whose results are interpreted according to methods published in technical literature or international standards. Concerning this class, the following tests will be used by the multi-agent system: electrical resistance, insulation resistance, power factor, frequency response analysis, depolarization and polarization current, partial discharges, degree of polymerization, recovery voltage measurement and tangens delta $(f)$.

Considering the variety and volume of data, besides particular characteristics of the previously cited tests, there is the necessity of interpreting and joining the results of these methodologies, so that the combined output is a more conclusive and reliable diagnosis about the transformer state.

\section{Multi-AGENT SYSTEMS}

Integrated diagnosis of power transformers requires the consideration of all available data and the application of a variety of different methods. The chosen approach must be able to handle large volumes of available information that is dynamical, unorganized and sometimes contradictory and/or dispersed around the network. A system designed for this purpose should also be able to provide human operators with decision-support, issuing important and meaningful conclusions, adequately adapted to each situation.
Multi-agent systems appear as a viable approach for this integration, as they are capable to handle large volumes of data, to convert data into meaningful information; and to supply the personnel with the right information at the right time [11].

MAS have been used with success in condition monitoring systems and other power system applications [12, 13]. They provide flexibility and extensibility, allowing additional data acquisition and monitoring systems to be incorporated in the future, offering an integrated approach to the design and implementation of diagnostic and condition monitoring applications [2].

\section{DITRANS APPROACH}

The architecture defined for the DITRANS system, presented in Figure 2, includes supervisory agents (off-line disconnected and off-line energized) in the conflict resolution layer. This characteristic permits a division between agents which undertake their tasks when the equipment is energized (e.g. DGA, FQ and 2-fal) or disconnected (e.g. RVM, PDC). Besides, the condition monitoring system uses distributed agents, with their respective diagnostic methods, which are not constrained by their physical location.

The resulting system integrates various monitoring technologies, diagnostic methods (which may be based on standard or artificial intelligence techniques) and data sources, such as dissolved gas analysis results (on-line or periodic measurements), and partial discharges measurements, among others.

Each layer of this diagnostic MAS contains a number of agents performing different functions. The social ability and cooperation between the agents leads to the final diagnosis and to other relevant conclusions. 


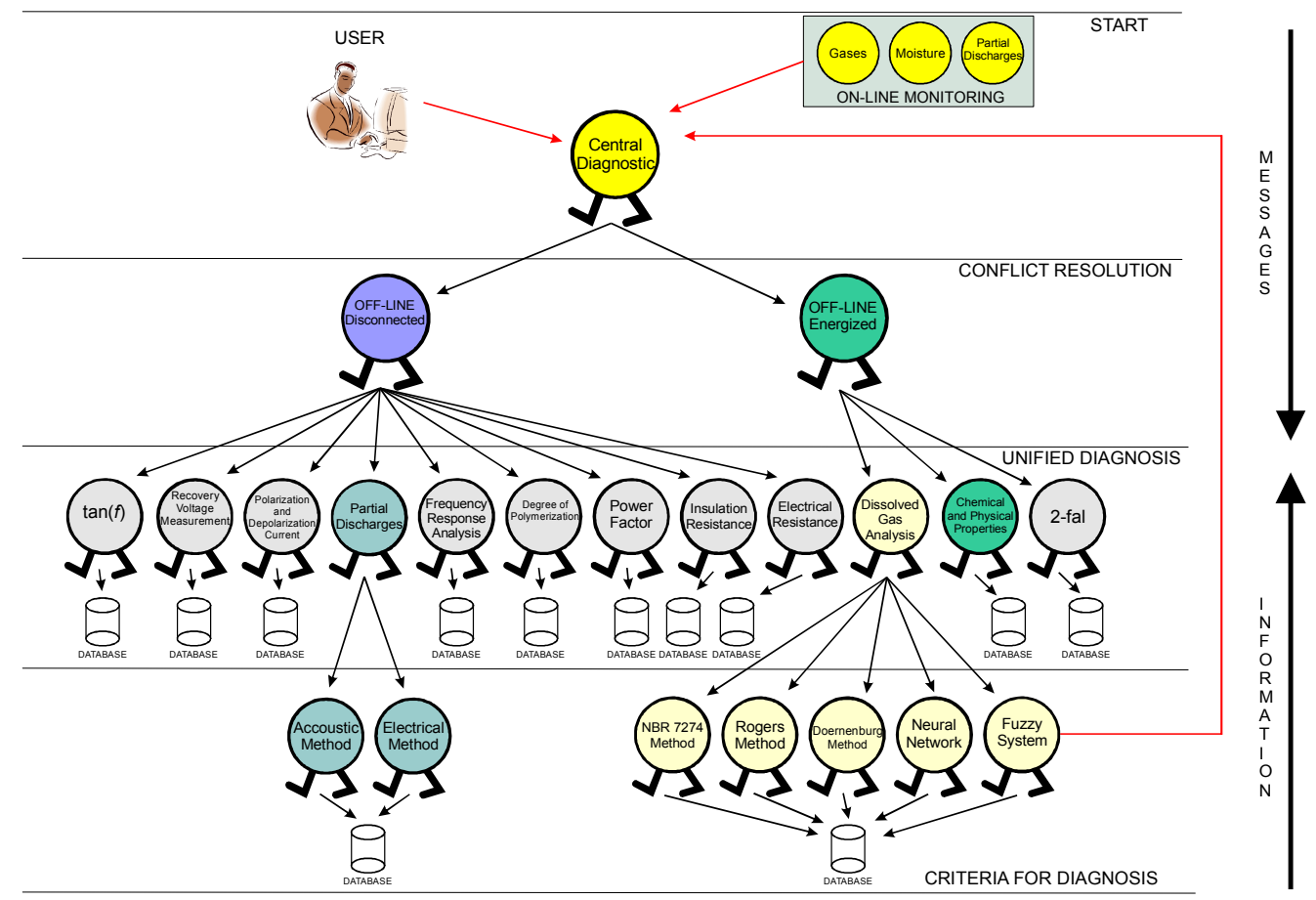

Fig. 2. DITRANS System Architecture.

Besides the application of all methodologies considered for each test, the developed multi-agent system is capable of keeping the physical distribution of information, not integrating them into the same framework, but accessing only the part of information that will be useful, from the databases installed at different laboratories. These laboratories are responsible for the realization of the tests in function of their nature (chromatographic laboratory, high voltage laboratory, low voltage laboratory).

Each agent has a response associated to the methodology or test it represents. The agent functionalities are determined as function of the system layer where it is inserted: start layer, conflict resolution layer, unified diagnosis layer and diagnosis for criterion layer.

\section{A. Start Layer}

The central diagnosis agent has the function of accessing data from off-line energized and disconnected agents. This agent can be initiated by three ways: by user request, as a response to a received warning signal (on-line monitoring) or when the fuzzy system detects a significant alteration in gases data, as shown in figure 2. This agent also gives information about all occurrences and available test results through the user interface.

\section{B. Conflict Resolution Layer}

This layer integrates the diagnosis provided by the agents by nature (off-line energized and disconnected), which interpret the received information from unified diagnosis agents. When necessary, these agents also are responsible for the conflict resolution about this information.
Tests lose validity with time, so this must be considered when using them for the diagnosis process. Thus, the validity of these data is calculated, as well as an index for the method importance for the determination of the certainty degree for each diagnosis.

The data validity is expressed by (1):

$D_{v}=-\left(\frac{\left(t-t_{\text {test }}\right)}{d_{v a l}}\right)+1$

Where:

$t$ - date for the diagnosis;

$t_{\text {test }}$ - date of the last test immediately previous to the date for the diagnosis;

$d_{v a l}$ - the maximum period (in days) in which the diagnosis is valid;

The method importance $M_{i}$ is a value determined by experts in the considered test.

The certainty degree can be calculated by (2):

$C_{d}=D_{v} * M_{i} * D_{d}$

Where:

$D_{v}$ - data validity;

$M_{i}$ - method importance;

$D_{d}$ - defect degree, determined in each methodology.

Each one of the considered defects has a fixed number of tests or methodologies which may be used for its detection. Each one of these methodologies has a certainty degree which should be calculated. The final diagnosis is obtained by the sum of all certainty degrees associated to the same defect, as 
shown in (3):

$$
D_{a}\left(C_{d 1}\right)+D_{a}\left(C_{d 2}\right)+\ldots . .+D_{a}\left(C_{d n}\right)=D_{a}\left(\frac{\sum_{1}^{n} C_{d}}{N}\right)=D_{a}\left(C_{d f}\right)
$$

Where:

$D_{a}$ - diagnosis of a state (defect or normality condition, identified by index $a$ ) obtained for each one of methods individually;

$C_{d 1}, C_{d 2}, \ldots, C_{d n}$ - certainty degree obtained by applying (2) to each method in the group of chosen diagnosis (identified by index);

$n$ - number of methods which can diagnose the defect in question;

$N$ - number of methods which can diagnose the defect in question, and which are connected at the system in the analysis moment;

$C_{d f}$ - final certainty degree obtained by the sum of certainty degrees associated to the methods with limit equal to 1 .

\section{Unified Diagnosis Layer}

There are fourteen diagnosis agents with the purpose of applying methodologies to interpret the results of a specific test and give a diagnosis.

When there is only one methodology associated to a test, the function of this agent is to supply its output and an associated certainty degree to its supervisory agents (off-line energized and off-line disconnected).

On the other hand, when there is more than one criterion for the evaluation of the equipment state associated to a single test, which can be based on standards, artificial intelligence techniques or other methods consolidated in technical literature, this agent has aims at solving conflicts and providing an integrated diagnosis, based on the outputs supplied by the agents in the inferior layer. In this case, the conflict is solved with the same procedure described in the conflict resolution layer.

\section{Criteria for Diagnosis Layer}

This layer includes auxiliary methods for diagnosis and involves mainly the dissolved gas analysis. These methods may be based on mathematical criteria, comparing current values of tests with historical values (Rogers, Doernenburg and NBR7274 Methods), or based on artificial intelligence techniques (neural network and fuzzy logic),, as shown in the figure 2. Each agent in this layer must supply one diagnosis related to only one test and with an associated certainty degree. These agents must be capable of accessing adequate databases to perform their task.

\section{V.RESULTS}

For evaluating the tool presented in this paper, a historical set of DGA and Chemical-Physical properties of insulating oil for a failed transformer obtained from a large Brazilian utility will
TABLE III

RESULTS OBTAINED

\begin{tabular}{l|l|l|c}
\hline \multicolumn{2}{c|}{ AGENT } & DiAgnOSTIC & $\begin{array}{c}\text { CERTAINTY } \\
\text { DEGREE }\end{array}$ \\
\hline \multirow{4}{*}{ DGA Agent } & NBR7274 Method & Arcing & 0.87 \\
\cline { 2 - 4 } & Rogers Method & Arcing & 0.97 \\
\cline { 2 - 4 } & Doernenburg Method & Arcing & 0.97 \\
\cline { 2 - 4 } & Neural Network & Overheating & 0.96 \\
\cline { 2 - 4 } & Fuzzy System & Arcing & 1.0 \\
\hline Frequency Response Analysis (FRA) & $\begin{array}{l}\text { Short Circuit in } \\
\text { the windings }\end{array}$ & 0.7 \\
\hline \multicolumn{2}{l}{ Chemical and Physical Properties(C-P) } & Contamination & 0.8 \\
\hline \multicolumn{2}{l|}{ Multi-agent System } & Arcing & $\mathbf{0 . 7 6}$ \\
\hline
\end{tabular}

be used. With the objective of integrating more than one method for the same purpose, the example also considers the frequency response analysis test.

The example chosen for showing the tool operation is totally automated, without necessity of user intervention, as described in the following summarized steps.

The agent which represents the fuzzy system sends a message to the diagnosis central informing that it has detected a gas formation above the limits permitted for the transformer with reference number 102-00482 in 11/03/2004. This agent suspects that there is arcing in oil. The multi-agent system interprets this warning signal and consults the agents concerning the methods related with this defect according to table I (DGA, C-P and FRA).

In the C-P test, the fault occurrence cannot be detected directly. The presence of contaminants can lead to arcing occurrence and its results must be used complementary to other tests, mainly DGA.

The arcing in the oil cannot be detected directly by the FRA either, but some short circuit in the windings can be responsible for the appearance of this defect in the oil, according to Table II and this result must be considered.

The DGA test is able to detect the arcing in oil directly by applying its methods. The multi-agent system considers the NBR7274, Rogers and Doernenburg methods, a neural network and a fuzzy system as auxiliary agents.

The results of each agent applied individually, as well as the integrated results of the system, can be seen in Table III.

\section{A. Results Validation}

In $11 / 03 / 2004$, the transformer evaluated by the tool (102-00482) was removed of operation due to a trip signal from Buchholz relay.

DGA tests were performed in the utility laboratories and the measurements can be visualized in Figure 3. The methods used by the utility indicated arcing in the oil.

After these tests, the transformer was disassembled in the plant, and a deformation and burn of coil 1 was identified. The fault was initiated by an external short circuit which caused short circuit in the windings. Figure 4 shows the medium voltage coil 1 , which was damaged. 
Dissolved Gas Analysis - 102-00482

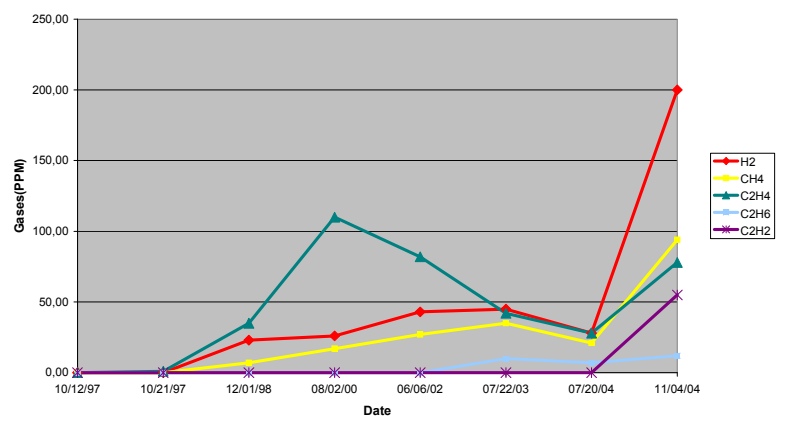

Fig. 3. Level of Generated Gas.

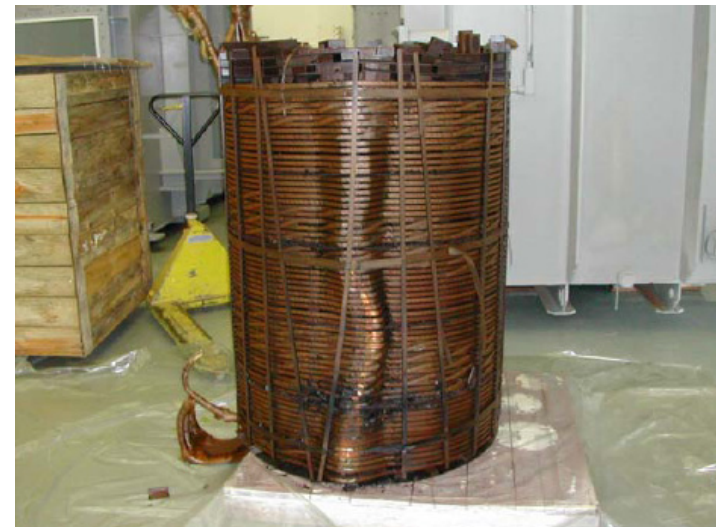

Fig. 4. Coil 1 damaged in the medium voltage winding.

\section{CONCLUSION}

This paper has proposed a multi-agent system (DITRANS) for the transformer diagnosis and condition monitoring. Due to the nature of the monitoring systems and the techniques used for the equipment evaluation, besides the physical distribution of the databases in electrical plant, many authors cite the condition evaluation and integration as a better alternative for the optimization of equipment availability.

DITRANS proved to be highly adequate to the problem because it can handle large volumes of data dispersed along the net, permits the integration of results provided by different software modules, and also allows the addition of other sensors and methodologies, without difficulties, in the future.

The results provided by the application of the system to a real case were satisfactory and in accordance with the inspection results realized after the fault occurrence, but further tests should be performed before the system is considered ready for real operation.

Finally, it should be pointed out that sometimes the interpretation of the tests results is very complex and demands the experience of the engineer responsible for the diagnosis.

\section{ACKNOWLEDGMENT}

The authors gratefully acknowledge M. Sc. Marco Marin and Energy Company in the Paraná State for the provision of the experimental data.

\section{REFERENCES}

[1] M. Wang, A. J. Vandermaar, K. D. Srivastava, "Review of Condition Assessment of Power Transformers in Service," IEEE Electrical Insulation Magazine, vol. 18, $\mathrm{n}^{\circ}$ 6, pp. 12-26, Nov.-Dec. 2002.

[2] S. Tenbohlen, D. Uhde, J. Poittevin, H. Borsi, P. Werle, U. Sundermann, H. Matthes, "Enhanced Diagnosis of Power Transformers using On- and Off-line Methods: Results, Examples and Future Trends," CIGRE Session, paper 12-204.

[3] J. A. Lapworth, P. N. Jarman, I. R. Funnell, "Condition Assessment Techniques for Large Power Transformers," in Proc. Of The Reliability of Transmission and Distribution Equipment Conference, Coventry, 1995, pp. 85-90.

[4] A. Setayesmehr, A. Akbari, H. Borsi, E. Gockenbach, "A Procedure for Diagnosis and Condition based Maintenance for Power Transformers," in IEEE International Symposium on Electrical Insulation, pp. 504-507.

[5] M. S. A. Minhas, J. P. Reynders, P. J. DeKlerk, "Failures in Power System Transformers and Appropriate Monitoring Techniques," in Eleventh International Symposium on High Voltage Engineering, vol.1, London, 1999, pp. 94-97.

[6] D. Chu, and A. Lux, "On-Line Monitoring of Power Transformers and Components: A Review of Key Parameters," in Electrical Insulation Conference and Electrical Manufacturing \& Coil Winding Conference. Proceedings, Cincinnati, 1999. pp. 669-675.

[7] IEEE Guide for Failure Investigation, Documentation, and Analysis for Power Transformers and Shunt Reactors, IEEE Std. C57.125-1991. New York.

[8] IEEE Guide for the Interpretation of Gases Generated in Oil-Immersed Transformers, IEEE Std. C57.104-1991. New York.

[9] D. R. Morais, J. G. Rolim, "A Hybrid Tool for Detection of Incipient Faults in Transformers Based on the Dissolved Gas Analysis of Insulating Oil," IEEE Transactions on Power Delivery, vol. 21, n² 2, pp. 673-680, Apr. 2006.

[10] NBR 7274 - Interpretation of Dissolved Gas Analysis of Transformers in Service - Procedures, (In Portuguese) April 1982.

[11] S. D. J. McArthur, and E. M. Davidson, "Multi-Agent Systems for Diagnostic and Condition Monitoring Applications," IEEE Power Engineering Society General Meeting, vol. 1, pp. 50-54, Jun. 2004.

[12] S. D. J. McArthur, S. M. Strachan, J. Gordon, "The Design of a MultiAgent Transformer Condition," IEEE Transactions on Power Systems, vol. 19, n ${ }^{\circ}$ 2, pp. 1845-1852, Nov. 2004.

[13] I. Praça, C. Ramos, Z. A. Vale, M. Cordeiro, "MASCEM: A MultiAgent System that Simulates Competitive Electricity Markets," IEEE Intelligent Systems, vol. 18, nº 6, pp. 54-60, Nov./Dec. 2003.

Diego Roberto Morais received the M.Sc. degree in electrical engineering in 2004 from Federal University of Santa Catarina, Florianópolis, Brazil. Currently, he is pursuing the Doctor Degree at the same university and is realizing a split Ph.D. program with UFSC and Polytechnic Institute of Porto, Porto, Portugal. His research areas include power transformers diagnosis and artificial intelligence

Jacqueline Gisèle Rolim received the B.S.E.E. and M.Sc. degrees in power systems from the Federal University of Santa Catarina (UFSC), Florianópolis, Brazil, in 1982 and 1988, respectively. She was in a split Ph.D. program with UFSC and Brunel University, Uxbridge, U.K., and received the Ph.D. degree in 1995. From 1985 to 1991, she worked on high-voltage (HV) and extremely high voltage (EHV) substation projects. Currently, she is an Associate Professor at UFSC, working on artificial intelligence applications to power system operation.

Zita A. Vale (M'86) received the B.Sc. degree in 1986 and the Ph.D. degree in electrical engineering in 1993 from the University of Porto, Porto, Portugal. She is currently a Coordinator Professor with the Polytechnic Institute of Porto, Porto, Portugal. Her research areas include power systems operation and control, electricity markets, decision support, and artificial intelligence. 